\title{
ALTERAÇÕES DA MATRIZ EXTRACELULAR ESPLÊNICA EM CÃES NATURALMENTE INFECTADOS COM Leishmania (Leishmania) infantum chagasi
}

\author{
CHANGES IN THE SPLENIC EXTRACELLULAR MATRIX IN DOGS \\ NATURALLY INFECTED WITH Leishmania (Leishmania) infantum chagasi
}

\author{
Nathálya dos Santos Martins ${ }^{1}$ \\ Glaucia Barbosa Coelho² \\ Larissa Sarmento dos Santos ${ }^{3}$ \\ Rudson Almeida de Oliveira ${ }^{4}$ \\ Ana Lúcia Abreu Silva ${ }^{4}$ \\ Ferdinan Almeida Melo ${ }^{4}$ \\ 1Pós-graduanda da Rede Nordeste de Biotecnologia (RENORBIO), São Luis, MA, Brasil - \\ veterinariamartins@hotmail.com \\ 2Médica Veterinária, Universidade Estadual do Maranhão, São Luis, MA, Brasil \\ ${ }^{3}$ Pós-graduanda da Rede Norte de Biotecnologia (BIONORTE), São Luis, MA, Brasil \\ ${ }^{4}$ Professores Doutores da Universidade Estadual do Maranhão, São Luis, MA, Brasil
}

\section{Resumo:}

Objetivou-se estudar as alterações da matriz extracelular no baço de cães naturalmente infectados com Leishmania (Leishmania) infantum chagasi correlacionando-as com aspectos clínicos, histopatológicos e parasitológicos. Foram utilizados 18 cães, divididos em três grupos: seis animais não infectados (grupo controle) e doze animais infectados. Todos sem raça e idade definidas, provenientes da região do Município de São Luis-MA. Cortes parafinados do baço foram corados pela Hematoxilina e Eosina (H\&E); Prata amoniacal de Gomori, para marcação das fibras reticulares e pela técnica Imuno-histoquímica da estreptoavidina-peroxidase para detecção de formas amastigotas de Leishmania. As análises morfométricas foram feitas utilizando-se o programa KS300 e o sistema de análise de imagens Kontron Elektronic/Carl Zeiss, Germany. Os resultados mostram que há um aumento significativo da deposição de fibras colágenas no baço quando comparadas aos animais controles, revelando diferenças significativas entre os animais sintomáticos e assintomáticos. Encontraram-se correlações positivas entre a presença do parasitismo tecidual e a deposição de colágeno. Os animais sintomáticos apresentaram uma maior deposição de colágeno no baço, que pode estar associada ao maior parasitismo tecidual encontrado. Os resultados demonstram que na leishmaniose visceral canina há uma fibrogênese intensa no baço, sendo esta associada ao parasitismo tecidual e a processos degenerativos decorrentes da doença.

Palavras-chave: baço; Leishmania; matrix extracelular.

\begin{abstract}
:
The aim of this study was to study the changes in the splenic extracellular matrix of dogs naturally infected with Leishmania (Leishmania) infantum chagasi and its correlation to clinical, histopathological, and parasitological aspects. Eighteen dogs were used, separated into three groups: six non-infected animals (control group) and twelve infected animals. The dogs had undefined breed and age, from the township region of São Luís-MA. Paraffined slices of the spleen were stained with
\end{abstract}


Hematoxilin and Eosin (H\&E); Gomori's ammoniacal Silver, to mark reticular fibers; and the Immunohistochemistry technique of streptavidin peroxidase to detect amastigote forms of Leishmania. The morphometrical analyses were done using the KS300 program and the images analysis system Kontron Elektronic/Carl Zeiss, Germany. The results showed that there is a significant increase in the deposition of collagen fibers in the spleen, compared to control animals, showing significant differences for symptomatic and asymptomatic animals. Positive correlations were found between the presence of the parasite in the tissue and collagen deposition. Symptomatic animals showed higher collagen deposition in the spleen, which can be associated to the high parasitism found in the tissue. The results showed that there is an intense fibrogenesis in the spleen in the canine visceral leishmaniasis, thus being associated to the parasitism of the tissue and the degenerative processes of the disease.

Keywords: extracellular matrix; Leishmania; spleen.

Recebido em: 04 abr. 2013.

Aceito em: 21 nov. 2014.

\section{Introdução}

As leishmanioses são doenças infecto-parasitárias causadas por protozoários pertencentes à ordem Kinetoplastida, à família Trypanosomatidae e ao gênero Leishmania ${ }^{(1,2)}$. Este gênero é digenético e se apresenta sob duas formas básicas: uma flagelada denominada promastigota, que é encontrada no tubo digestório do inseto vetor e em alguns meios de cultura e outra forma sem flagelo externo, denominada amastigota, que é intracelular obrigatória, encontrada nas células do sistema fagocitário dos hospedeiros vertebrados ${ }^{(3,4)}$.

A Leishmaniose Visceral Canina (LVC) caracteriza-se por apresentar um largo espectro de lesões que varia desde a infecção inaparente até uma forma clinica severa, que normalmente leva à morte do animal. As principais lesões da leishmaniose visceral ocorrem em órgãos ricos em células do sistema monocítico mononuclear como baço, fígado, linfonodos, medula óssea, rins, pulmões, intestinos e pele $\mathrm{e}^{(5-8)}$.

O baço pode apresentar tamanho normal, discretamente aumentado ou hipertrofiado ${ }^{(9,10)}$. Neste órgão ocorre diminuição do número de linfócitos e proliferação de macrófagos na bainha linfóide periarteriolar, hiperplasia folicular e aumento da polpa vermelha com agregados de macrófagos e células plasmáticas ${ }^{(8,11,12)}$. A matriz extracelular (MEC), composta por proteínas fibrosas (colágeno e elastina), proteoglicanos, glicosaminoglicanos e proteínas estruturais, é um complexo estrutural que cerca e apoia as células encontradas nos tecidos sendo referida geralmente como tecido conjuntivo ${ }^{(13)}$. A formação e a degradação da matriz extracelular são processos dependentes e balanceados do mesmo tipo de célula. $\mathrm{O}$ excesso de acúmulo de MEC que leva à fibrose ocorre quando a formação que excede a degradação. As inflamações crônicas, uma consequência comum das infecções parasitárias, são um potente promotor de formação de matriz extracelular ${ }^{(14)}$. McGwire et al. ${ }^{(15)}$ mostraram que a migração de Leishmania spp. in vitro através da MEC ocorre devido à metaloprotease, que é capaz de mediar a proteólise da fibronectina e colágeno de tipo IV.

Os colágenos são as proteínas mais abundantes encontradas no reino animal, sendo as maiores proteínas constitutivas da MEC. O sistema colágeno é formado por vários tipos de colágenos 
geneticamente distintos que ocorrem em diferentes tecidos conjuntivos ${ }^{(16)}$. Abreu-Silva et al. ${ }^{(17)}$ demonstraram em trabalhos com infecção experimental em camundongos com L. amazonensis que, na pele, houve substituição do colágeno do tipo I pelo tipo III com o decorrer da infecção, com alterações da arquitetura normal deste órgão.

O objetivo desta pesquisa foi o estudo das alterações da matriz extracelular no baço de cães naturalmente infectados com Leishmania (Leishmania) infantum chagasi correlacionando estes achados com os aspectos clínicos, histopatológicos e parasitológicos.

\section{Material e Métodos}

Foram utilizados 18 cães provenientes do Centro de Controle de Zoonoses de São Luís - MA, Brasil, sendo doze cães soropositivos para Leishmania, detectados através de testes de imunofluorescência indireta (RIFI) e imunoensaio enzimático (ELISA - enzyme linked immunoaborbent assay) e seis cães com sorologia, exame parasitológico e PCR negativos para Leishmania.

Os cães foram clinicamente classificados e divididos em três grupos: Grupo 1 - animais sintomáticos - seis animais, todos sem raça e idade definidas, com vários sinais clássicos da doença, tais como: anemia, caquexia, alterações cutâneas (alopecia, eczemas ou úlceras), onicogrifose, ceratoconjuntivite, linfadenopatia, rigidez dos membros posteriores; Grupo 2 - animais assintomáticos - seis animais, sem raça e idade definidas sem sinais clínicos da doença; Grupo 3 animais controle - seis cães adultos, sem idade e raça definidas, com exame sorológico, parasitológico e PCR negativos para Leishmania. O protocolo experimental com cães foi aprovado pelo Comitê de Ética e Experimentação Animal (CEEA) da Universidade Estadual do Maranhão (UEMA), n ${ }^{\circ}$ protocolo 012/2009.

Para confirmar o diagnóstico negativo dos animais controle, foram coletadas amostras de sangue com EDTA e em seguida foi realizado o procedimento de extração do DNA utilizando-se o kit WizardTM Genomic DNA Purification Kit (Promega, Madison, WI, USA), seguindo-se as recomendações do fabricante. O DNA extraído foi amplificado em termociclador utilizando-se os primers RV1 (senso; 5'-CTTTTCTGGTCCCGCGGGTAG-3') e $\quad$ o $\quad$ RV2 (anti-senso; 5'CCACCTGGCCTATTTTACACCA-3'), previamente descrito por LACHAUD et al. ${ }^{(18)}$. O alvo dos primers é uma região conservada do kDNA de $L$. (L.) infantum chagasi e produzem um fragmento de aproximadamente 145 pares de base. Foi realizada PCR convencional, cuja reação total é de $25 \mu \mathrm{L}$, sendo 12,5 $\mu \mathrm{L}$ de PCR Master mix Promega ${ }^{\circledR}$ (Taqpolymerase, dNTPs, $\mathrm{MgCl}_{2}$, buffer); 1,5 $\mu \mathrm{L}$ de cada primer (10 pmol); $4,5 \mu \mathrm{L}$ de água DNAse e RNAsefree; e $5 \mu \mathrm{L}$ de amostra de DNA extraída. Em cada reação foram utilizados controles positivo (cão sorologicamente e parasitologicamente positivo para Leishmania infantum chagasi) e negativo. Os parâmetros utilizados para PCR foram: desnaturação inicial a $94{ }^{\circ} \mathrm{C}$ por 4 minutos; 40 ciclos de desnaturação $\left(94{ }^{\circ} \mathrm{C}\right.$ por 30 segundos), anelamento $\left(59^{\circ} \mathrm{C}\right.$ por 30 segundos); extensão $\left(72{ }^{\circ} \mathrm{C}\right.$ por 30 segundos); e extensão final a $72{ }^{\circ} \mathrm{C}$ por 10 minutos. Os produtos de PCR foram avaliados em gel de agarose a $1 \%$, conforme descrito na análise do DNA, utilizando-se marcador de peso molecular de 100 pb (1Kb DNA ladder Promega®), programação na cuba de eletroferese de $100 \mathrm{~V}, 75 \mathrm{~mA}, 50 \mathrm{~W}$ e 50 minutos de corrida. Em seguida, os amplificados foram visualizados em transiluminador.

Após centrifugação das amostras de soro sanguíneo, foram determinadas as concentrações séricas de atividades séricas de alanina aminotransferase (ALT), aspartato aminotransferase (AST) utilizando- 
se Kits bioquímicos veterinários específicos (Labtest@), seguindo recomendações do fabricante e a leitura foi realizada em analisador bioquímico semi-automático (Bio 2000-Bioplus) ${ }^{(19)}$.

Os animais foram tranquilizados com Acepromazina 1\%, na dosagem de $0,1 \mathrm{~mL} / \mathrm{kg}$ de peso por via intravenosa. Após 10 minutos, foi administrado anestésico geral, Tiopental Sódico 2,5\%, na dose de $0,5 \mathrm{~mL} / \mathrm{kg}$ de peso pela via intravenosa. O aspirado medular foi obtido por punção da extremidade inferior do esterno. O conteúdo medular foi aspirado com agulha descartável, 12x40, acoplada à seringa descartável de $20 \mathrm{~mL}$. Os esfregaços medulares, por sua vez, foram confeccionados em duplicata e corados por solução de Giemsa a $10 \%$.

Para a realização da eutanásia, os animais foram anestesiados com Acepromazina 1\%, na dosagem de $0,1 \mathrm{~mL} / \mathrm{kg}$ de peso por via intravenosa e, após 10 minutos, com o anestésico geral, Tiopental Sódico $2,5 \%$, na dose de $0,5 \mathrm{~mL} / \mathrm{kg}$ de peso por via intravenosa. Depois de atingido o plano anestésico adequado foi administrada uma dose letal $(0,3 \mathrm{~mL} / \mathrm{Kg})$ de T-61 ${ }^{(20)}$. Durante a necropsia, os órgãos foram analisados macroscopicamente, levando-se em consideração critérios como tamanho, peso e presença de lesões. Em seguida, foram retirados fragmentos do baço. Foram realizados esfregaços por aposição e os fragmentos foram preservados em formol tamponado a 10\% - pH 7,2 para inclusão em parafina.

As lâminas contendo cortes parafinados do baço foram coradas pela técnica da hematoxilina e eosina e analisadas por microscopia óptica. As alterações avaliadas no baço foram o espessamento e inflamação da cápsula, hipertrofia e hiperplasia da polpa branca e da polpa vermelha, congestão, deposição de hemossiderina e depleção de áreas T dependentes na polpa branca.

A presença de parasitos no órgão foi avaliada pelo método de imunohistoquímica, utilizando-se a técnica da estreptoavidina-peroxidase ${ }^{(21)}$. A análise foi quantitativa levando-se em conta o número de amastigotas encontrado em vinte campos observados (40x) ao microscópio óptico.

Utilizou-se para marcação das fibras colágenas a técnica histoquímica Prata Amoniacal de Gomori na qual as fibras são destacadas em preto. Os cortes histológicos do baço foram analisados para quantificar as fibrilas colágenas e reticulares quantificadas. Após cada marcação, foram capturadas 20 imagens aleatórias do corte histológico de cada animal, utilizando-se uma microcâmera JVC TK1270/RGB e, em seguida, digitalizadas na objetiva de 40X para a criação de um banco de imagens. Todos os campos marcados foram contados com o auxílio do software KS300 contido no analisador de imagens Kontron Elektronick / Carl Zeiss ${ }^{(22)}$.

Os dados, após tabulados, foram submetidos à análise estatística utilizando-se o software PRISM versão 3.0. Baseando-se na natureza da distribuição não-paramétrica dos dados obtidos para o parasitismo dos animais, para as análises de inferência entre dois dos grupos estudados, foi utilizado o teste de Mann-Whitney e para as análises de correlação o teste aplicado foi o Coeficiente de Correlação de Spearman.

Dados obtidos para a expressão das fibras reticulares apresentaram distribuição normal, sendo as inferências desses dados, quando para dois grupos, realizadas pelo teste-T, para mais de dois grupos realizadas no teste de variância da Tabela ANOVA, e as análises de correlação pelo Coeficiente de Correlação de Pearson e pela matriz de correlação de Pearson com índice de significância menor que $5 \%$. 


\section{Resultados e Discussão}

Um amplo espectro de lesões e alterações histopatológicas pôde ser observado durante a infecção pela L. (L.) infantum chagasi. Em cães, as alterações associadas à pele, como descritas na literatura, foram amplamente encontradas, destacando-se a descamação seca e a alopecia. Além disso, quando consideramos as alterações da pele em conjunto (descamação, alopecia, seborréia e ulcerações), estas passam a ser predominantes, o que está de acordo com o descrito por Ciaramella et al. ${ }^{(23)}$, Ferrer et al. ${ }^{(24)}$, Lima et al. ${ }^{(8)}$, Giunchetti et al. ${ }^{(25)}$ e Moura et al. ${ }^{(26)}$.

A análise dos dados revelou que houve diferença significativa na dosagem da ALT entre os grupos de animais controles e sintomáticos ( $\mathrm{p}<0,01$, teste $\mathrm{T}$ de Tukey) e entre animais dos grupos assintomáticos e sintomáticos ( $\mathrm{p}<0,05$, teste $\mathrm{T}$ de Tukey) para a mesma enzima. Não houve diferença significativa para o parâmetro AST entre os grupos estudados (Tabela 01).

Tabela 1: Avaliação dos parâmetros bioquímicos e enzimáticos em cães naturalmente infectados com $L$. (L.) infantum chagasi e animais não infectados

\begin{tabular}{lcc}
\hline \multirow{2}{*}{ Grupos } & \multicolumn{2}{c}{ Parâmetro Bioquímico (mg/dL) } \\
\cline { 2 - 3 } & AST / TGO & ALT / TGP \\
\hline Controle & $61,70 \pm 8,46$ & $29,70 \pm 7,32^{\mathrm{c}}$ \\
Assintomático & $68,60 \pm 21,23$ & $41,90 \pm 11,31^{\mathrm{a}}$ \\
Sintomático & $95,30 \pm 38,97$ & $130,00 \pm 110,59^{\mathrm{b}}$ \\
\hline Os resultados expressos como média dos valores \pm desvio-padrão. As diferenças estatisticamente \\
significativas (p<0,01 e p<0,05) referem-se às letras a,b e c.
\end{tabular}

As alterações macroscópicas observadas nos cães dos grupos sintomáticos e assintomáticos foram o aumento de volume do baço (esplenomegalia), o espessamento das bordas, o aspecto rugoso e irregular da superfície e a coloração vermelho-escura, sugerindo um quadro de congestão. Este fato comprovou-se ao corte, pois a polpa vermelha era friável e muitas vezes difluente. A polpa branca, na grande maioria dos casos, era facilmente visualizada como pontos de coloração brancacenta distribuídos difusamente na superfície do órgão, indicando a hipertrofia e hiperplasia dos folículos de Malpighi (hiperplasia folicular).

O peso relativo do baço dos animais assintomáticos, sintomáticos e dos cães do grupo controle é apresentado na Tabela 2, onde se pode observar que não houve diferença estatística significativa em relação ao peso relativo do baço entre os animais dos grupos assintomáticos e sintomáticos. Entretanto, houve diferença significativa dos pesos relativos dos baços desses dois grupos quando comparados ao controle. 
Tabela 2: Peso relativo (peso do baço/peso corporal) dos baços dos animais dos grupos assintomáticos, sintomáticos naturalmente infectados com L. (L.) infantum chagasi e do grupo controle

\begin{tabular}{l|c}
\hline Grupos & $\begin{array}{c}\text { Peso relativo (\%) } \\
\text { (média } \pm \text { SR) }\end{array}$ \\
\hline Controle & $0,101^{\mathrm{b}} \pm 0,0132$ \\
Assintomático & $0,257^{\mathrm{a}} \pm 0,0496$ \\
Sintomático & $0,354^{\mathrm{a}} \pm 0,0934$ \\
\hline
\end{tabular}

Os resultados estão expressos como médias dos valores \pm erro-padrão. As diferenças estatisticamente significativas referem-se às letras a, b. ANOVA $\mathrm{p}<0,0001$.

As alterações histopatológicas observadas no baço dos cães foram o espessamento e inflamação da cápsula, a hiperplasia e hipertrofia da polpa branca e da polpa vermelha, a congestão da polpa vermelha, a deposição de pigmentos de hemossiderina e a depleção da bainha periarteriolar na polpa branca, em alguns casos (Figura 01). No baço, a congestão era observada macroscopicamente pela coloração e a fluidez de sangue ao corte do órgão foi um achado comum e comprovado quando observado ao microscópio óptico. O espessamento da cápsula, assim como a inflamação capsular e subcapsular foram observados, principalmente, nos animais sintomáticos. Todavia, a hipertrofia e hiperplasia da polpa branca ocorreram em todos os grupos estudados, principalmente nos animais sintomáticos e assintomáticos. Essas alterações encontram-se descritas na literatura sobre animais naturalmente e experimentalmente infectados ${ }^{(6)}$.

Os fragmentos de baço analisados apresentaram espessamento e inflamação da cápsula, com graus variados de intensidade. A polpa branca era evidente apresentando folículos linfóides constituídos por células dispostas em diferentes camadas, de acordo com sua afinidade tintorial. As células mais centrais eram claras com núcleos vesiculosos e citoplasma acidófilo contendo ou não parasitos. As células periféricas eram mais escuras evidenciando seus núcleos bem corados pela hematoxilina \& eosina (Figura 01).

Depleção de áreas T dependentes, bainha periarteriolar da polpa branca, no baço de hamsters e cães experimentalmente infectados com L. donovani, foram descritos por Corbett et al. ${ }^{(27)}$, sendo que esses animais certamente desenvolveram algum grau de imunodepressão. Neste trabalho, essa alteração foi observada em alguns dos animais sintomáticos; entretanto, na região de polpa vermelha, grande número de macrófagos parasitados pode ser observado tanto em animais do grupo sintomático quanto nos assintomáticos. A presença de macrófagos, altamente parasitados no parênquima de órgãos linfóides de animais assintomáticos, é também descrita por outros autores como Abranches et al. ${ }^{(28)}$; Lima et al. ${ }^{(8)}$ e Xavier et al. ${ }^{(29)}$. Na leishmaniose visceral ocorre o desenvolvimento de uma resposta imune órgão-específica em dois principais órgãos alvos de infecção - o baço e o fígado.

A polpa vermelha sofreu modificações, devido ao aumento considerável do número de células, tanto de macrófagos marginais dos seios quanto dos cordões de Billroth e da pronunciada neoformação conjuntiva (fibroblastos jovens e fibrócitos), levando à redução da luz dos seios. Todos os cães dos grupos sintomáticos e assintomáticos analisados apresentaram quadro de hiperplasia e hipertrofia da polpa vermelha.

Estudos indicam que o baço, considerado local inicial da geração da resposta imune mediada por células, também parece ser o local de persistência do parasito associada com modificações 
imunopatológicas. Estas incluem esplenomegalia e distúrbios na arquitetura tecidual que parecem contribuir para o estado de imunocompetência do hospedeiro ${ }^{(30,31)}$.

Parasitos imunomarcados foram facilmente visualizados nos macrófagos sinusoidais (Figura 02).
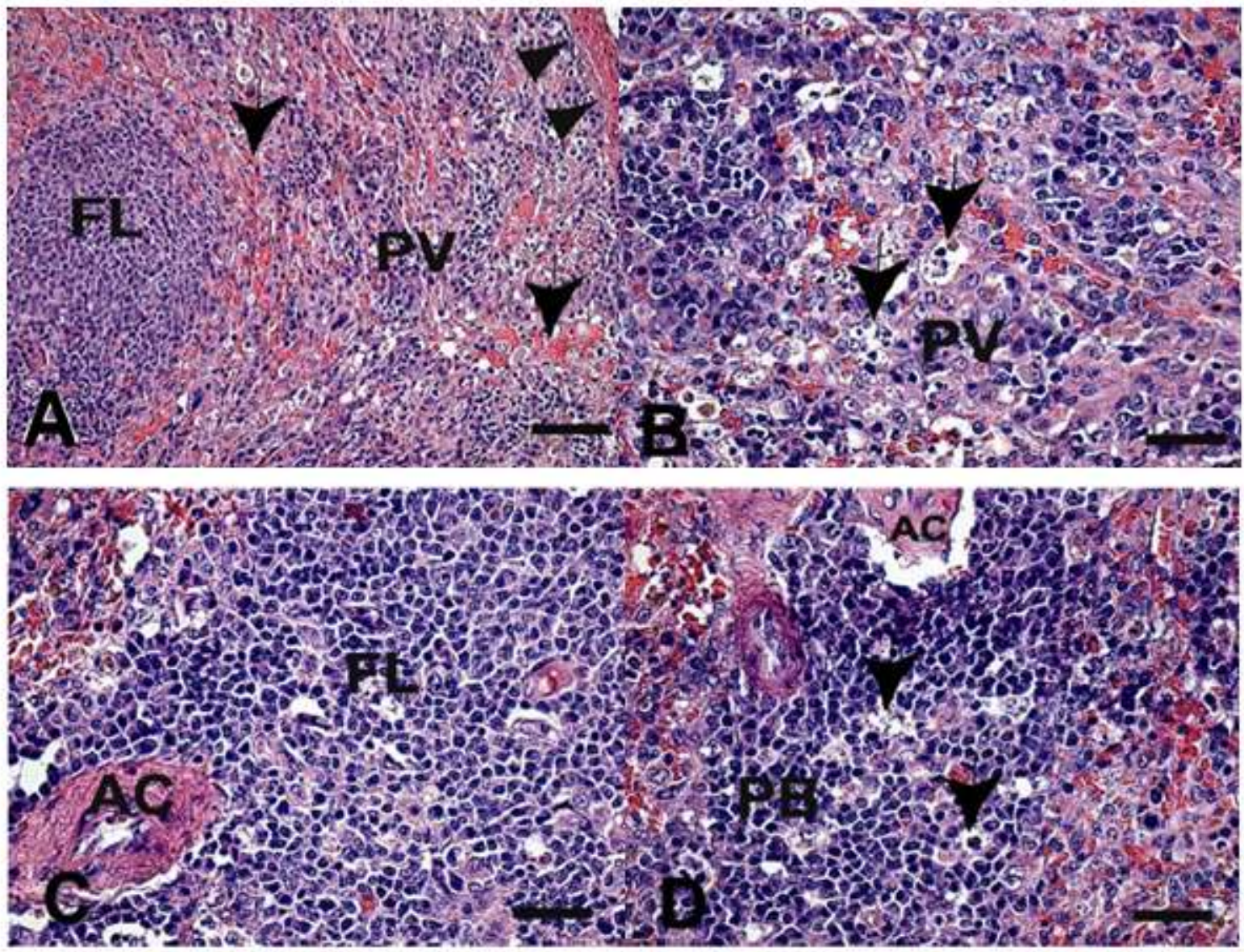

Figura 01: Cortes Histológicos de baço de cães naturalmente infectados $\operatorname{com} L$. (L.) infantum chagasi: (A, B, C) Cão Assintomático: (A) cápsula espessada (cabeças de seta), polpa vermelha congesta (setas) e polpa branca reativa, apresentado folículo linfóide evidente. ( $B, C$ ) detalhes da figura anterior, sendo em (B) região da polpa vermelha contendo macrófagos hipertróficos e vacuolizados, com alguns deles repletos de formas amastigotas de Leishmania (setas). Em (C): detalhe das células do folículo linfóide (polpa branca reativa). (D) Cão Sintomático: folículo linfóide sem formação de centro germinativo e com diminuição numérica de linfócitos, sendo esses substituídos por macrófagos intensamente parasitados por formas amastigotas de Leishmania (setas). Hematoxilina \& Eosina, $(\mathrm{A})$ Barra $=32 \mu \mathrm{m}$ e $(\mathrm{B}, \mathrm{C}, \mathrm{D})$ Barra $=16 \mu \mathrm{m})$. FL (Folículo Linfóide); PB (Polpa Branca); PV (Polpa Vermelha); AC (Arteríola Central). 


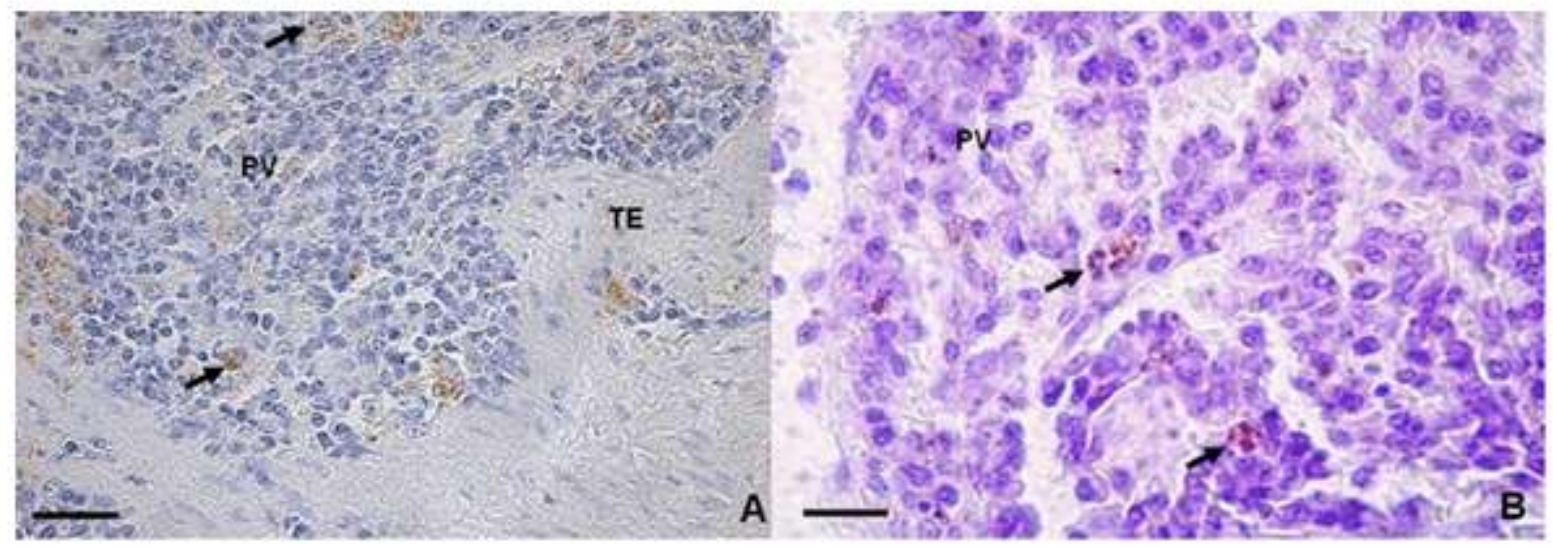

Figura 02: Cortes Histológicos de baço de cães naturalmente infectados com $L$. (L.) infantum chagasi: (A, B) Cães sintomáticos: presença de formas amastigotas imunomarcadas na polpa vermelha (PV) (setas). Estreptoavidina-Peroxidase. (A) Barra $=16 \mu \mathrm{m}$, (B) Barra $=10 \mu \mathrm{m}$. TE (Trabécula Esplênica).

A presença das formas amastigotas de Leishmania no baço detectadas pela técnica imunohistoquímica estreptoavidina peroxidase, foi avaliada pela carga parasitária determinada pela contagem de parasitos por um determinado número de campos analisado pelo Teste T não pareado. Os resultados mostraram que houve diferença significativa entre os grupos de cães sintomáticos e assintomáticos $(\mathrm{p}=0,0023)$ (Figura 03).

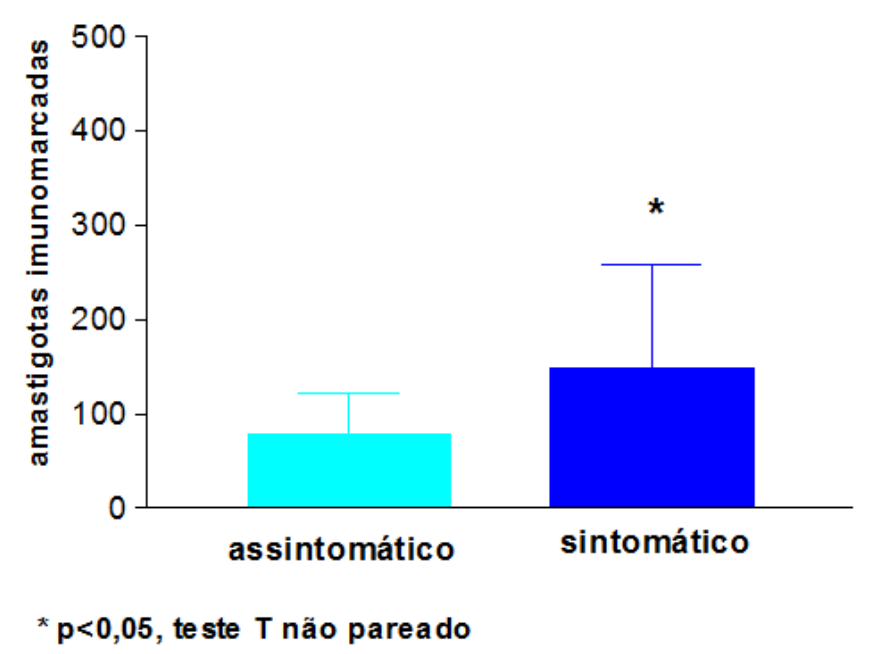

Figura 03: Número de amastigotas marcadas por imunohistoquímica no baço entre grupos sintomáticos e assintomáticos $(* \mathrm{p}=0,0023$ Teste t não pareado).

As principais alterações da matriz extracelular observadas no baço dos cães dos grupos sintomático e assintomático foi o aumento significativo tanto da espessura quanto da quantidade de colágeno depositado na cápsula, assim como o aumento da deposição de fibras reticulares no parênquima esplênico ao serem comparados os dois grupos de animais infectados com o grupo controle (Figura 
04). Evidenciou-se neste estudo a maior deposição de fibras reticulares no baço dos cães dos grupos sintomáticos e assintomáticos em relação ao grupo de animais controle, resultados estatisticamente significativos ao se comparar a deposição colagênica entre todos os grupos. No baço dos animais sintomáticos foi quantificada a maior deposição, sendo que, nesses animais, as fibras reticulares apresentavam maior grau de espessamento, formando uma trama mais densa.

$\mathrm{O}$ acúmulo de MEC que leva à fibrose ocorre quando a formação excede a degradação. Nas inflamações crônicas, consequência comum das infecções parasitárias, é um potente promotor de formação de matriz extracelular ${ }^{(14)}$. Dessa forma, a fibrogênese intensa observada nos baços dos animais infectados (sintomáticos e assintomáticos) poderia estar diretamente ligada à carga parasitária e às alterações histológicas encontradas neste órgão. Adicionalmente, a esplenomegalia foi mais preponderante nos animais sintomáticos que apresentaram maior carga parasitária.
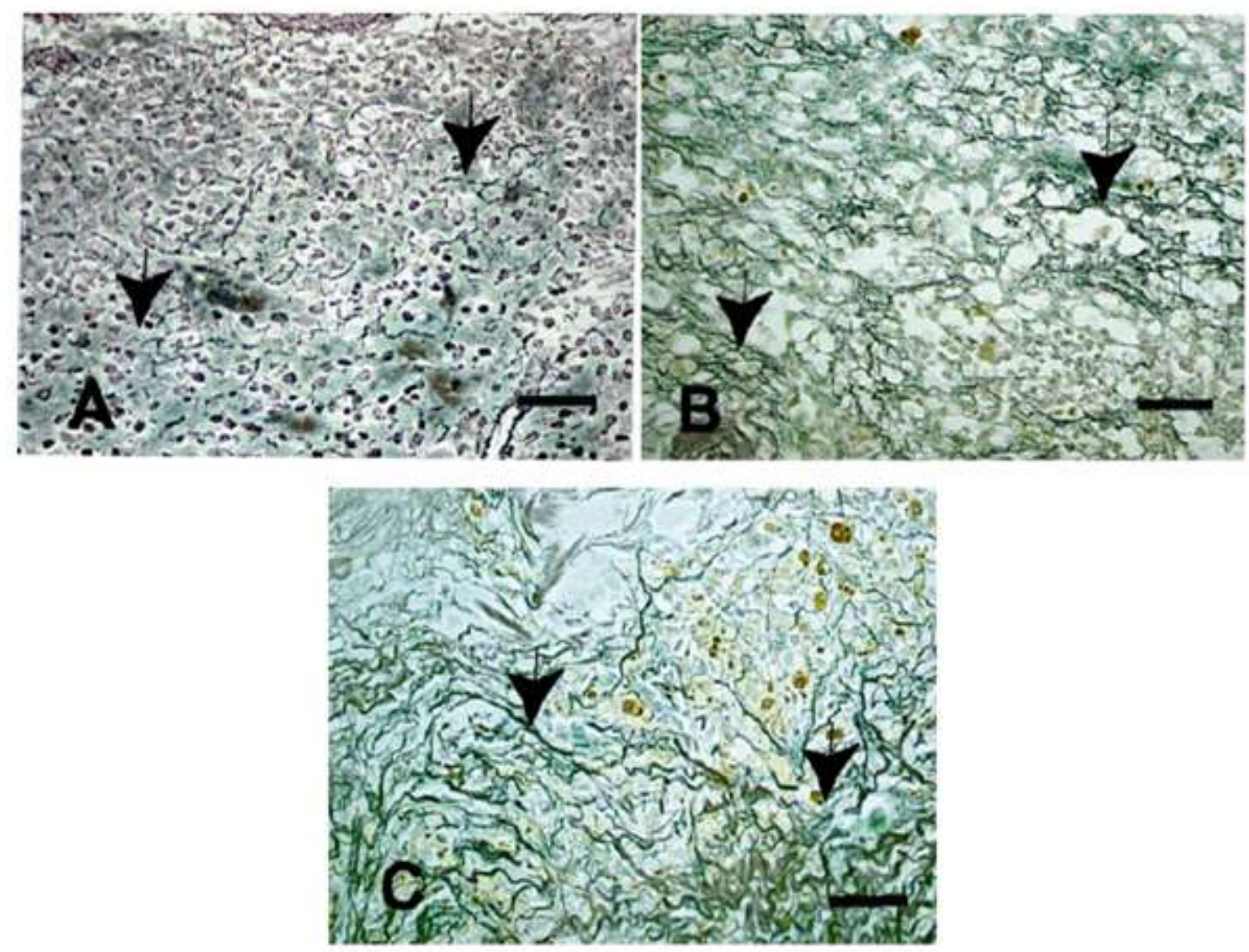

Figura 04: Cortes histológicos parafinados de baço de cães controle (A) e cães naturalmente infectados com L. (L.) infantum chagasi (B e C): (A): Cão Controle. Delicada rede de fibras reticulares (setas). (B): Cão assintomático: Fibras colágenas mais proeminentes podem ser observadas (setas). (C): Cão sintomático: Fibras reticulares espessadas e mais evidentes podem ser observadas (setas). Prata Amoniacal de Gomori. (A e B) Barras $=16 \mu \mathrm{m}$.

Houve diferença estatística significativa entre os grupos sintomáticos e assintomáticos $(\mathrm{p}<0,0001$, ANOVA; teste $t$ de Student $\mathrm{p}<0,01)$. Também observaram-se resultados significativos entre os 
animais do grupo sintomático e controle; assim, não houve diferença apenas quando comparada a deposição das fibras reticulares entre os grupos de cães assintomáticos e controle (Figura 05).

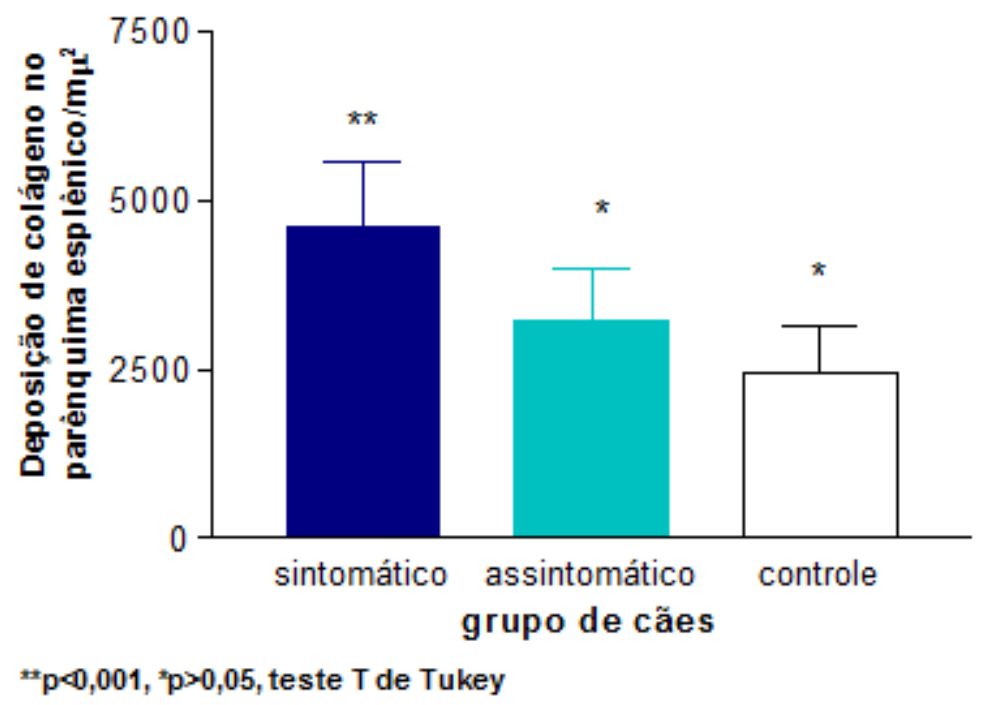

Figura 05: Deposição de colágeno no parênquima esplênico dos grupos de cães estudados.

A deposição de colágeno no parênquima esplênico marcada pela técnica da prata amoniacal de Gomori mostrou correlação positiva com o parasitismo do baço. A correlação foi significativa ao teste de correlação de Pearson ( $\mathrm{r}=0,6531, \mathrm{p}=0,00213$ ) (Figura 06).

Outra explicação para a intensa congestão e colapso estrutural do parênquima, que contribuiria para o aumento de peso e de tamanho esplênico, assim como a deposição de fibras reticulares na leishmaniose visceral canina demonstrado por Weiss et al. ${ }^{(32)}$ e Alexandre-Pires et al. ${ }^{(33)}$, é que a presença de maior número de células reticulares que formam o leito de filtração sinusoidal seria responsável por vários mecanismos como controle da circulação do baço através da contração, alinhamento da expansão das células dendríticas e reticulares promovendo a síntese de colágeno do tipo III (fibras reticulares).

Uma rede de fibras reticulares pôde ser observada nas condições de parasitismo esplênico na leishmaniose visceral. Esse evento estaria provavelmente envolvido no impedimento ou na diminuição do fluxo de elementos sanguíneos através do leito de filtração e, consequentemente, o trânsito dos parasitos pelo baço. Esse mecanismo reticular parece ser efetivo na origem da condição de stress, pela queda no fluxo sanguíneo, assim como no mecanismo imunológico esplênico. O colapso da arquitetura sinusoidal pode ser responsável pelo processo congestivo inicial e aumento massivo típico do órgão na leishmaniose visceral. 


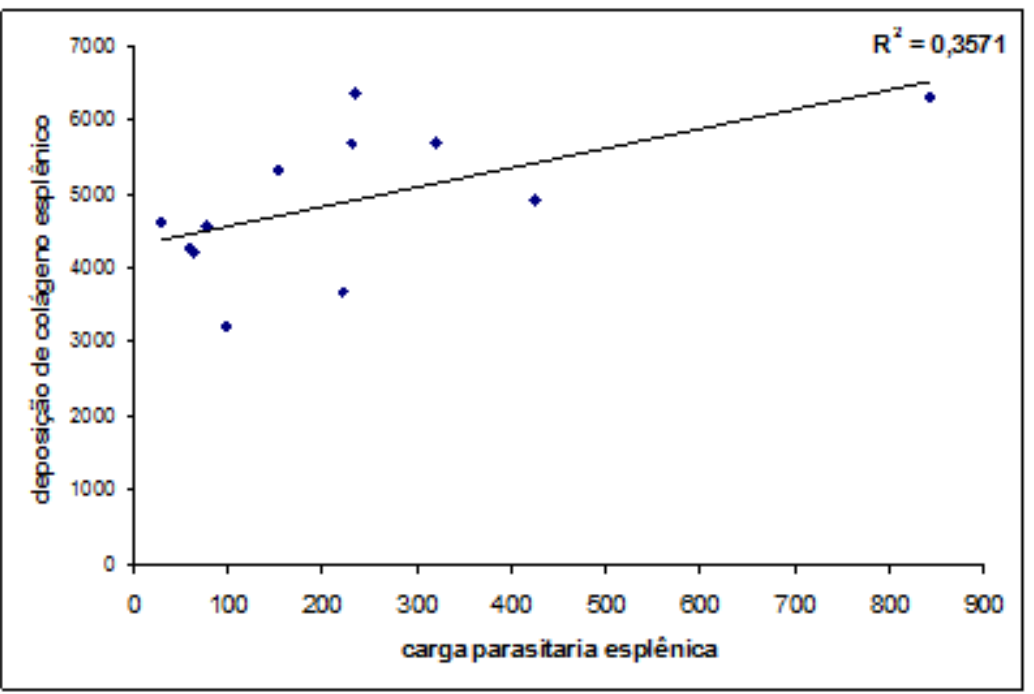

Figura 06: Correlação entre o parasitismo esplênico de cães naturalmente infectados com L. (L.) infantum chagasi (avaliado por imunohistoquímica) e a deposição de colágeno na cápsula do baço (Prata Amoniacal de Gomori).

\section{Conclusões}

Os animais naturalmente infectados por $L$. (L.) infantum chagasi apresentam aumento da deposição de matriz extracelular do baço em relação ao grupo controle, não infectado. Tanto o parasitismo tecidual, quanto o caráter inflamatório encontrado nos tecidos estudados correlacionam-se com as alterações da matriz extracelular do baço na leishmaniose visceral canina. Os animais do grupo sintomáticos apresentaram maior grau de alterações de matriz intersticial no baço.

\section{Agradecimentos}

À Fundação de Amparo à Pesquisa e ao Desenvolvimento Científico e Tecnológico do Maranhão (FAPEMA), CNPq e PROCAD NF/CAPES.

\section{Referências}

1. Ross, R. Note on the bodies recently described by Leishman-Donovan and (2) Further notes on Leishman's bodies. British Medical Journal. 1903 Nov 14; 2(2237): 1261-2. Disponível em: http://www.ncbi.nlm.nih.gov/pmc/articles/PMC2514667. Inglês.

2. Sundar, S \& Rai, M. Advances in the treatment of leishmaniasis. Current Opinion in Infectious Diseases. 2002 Dec; 15(6): 593-8. Disponível em: http://journals.lww.com/coinfectiousdiseases/Abstract/2002/12000/Advances_in_the_treatment_of_leishmaniasis.7.aspx. Inglês.

3. Lainson R, Ryan L, Shaw JJ. Infective stages of Leishmania in the sandfly vector and some observations on the mechanism of transmission. Memórias do Instituto Oswaldo Cruz. 1987 Jul-Sep; 82(3): 421-4. Disponível em: http://memorias-old.ioc.fiocruz.br/vol82(f3)_105-108.pdf. Inglês.

4. Killick-Kendrick, R. The life-cycle of Leishmania in the sandflay with special reference to the form 
infective to the vertebrade host. Annales de Parasitologie Humaine et Comparee. 1990; 65 Suppl 1:37-42.

5. Bogliolo, L. Nova contribuição ao conhecimento da anatomia patológica da leishmaniose visceral. A propósito de um caso brasileiro e com especial referência a fibrose hepática leishmaniótica. O Hospital. 1956; 3:101-4.

6. Tafuri, W.L.; Tafuri, W.L.; Barbosa, A.J.A.; Michalick MS.; Genaro O.; Franca-Silva JC.; Mayrink W.; Nascimento E. Histopathology and immunocytochemical study of type 3 and type 4 complement receptors in the liver and spleen of dogs naturally and experimentally infected with Leishmania (Leishmania) chagasi. Revista do Instituto de Medicina Tropical de São Paulo. 1996 Mar-Apr; 38(2): 81-9. Disponível em: http://www.scielo.br/pdf/rimtsp/v38n2/a01v38n2.pdf. Inglês.

7. Tafuri, W.L.; de Oliveira M.R.; Melo, M.N.; Tafuri, W.L. Canine visceral leishmaniasis: a remarkable histopathological picture of one case report from Brazil. Veterinary Parasitology. 2001 Apr 2; 96(3): 203-12. Disponível em: http://www.scielo.br/pdf/abmvz/v58n6/04.pdf. Inglês.

8. Lima, W.G.; Michalick, M.S.; Melo, M.N.; Tafuri, W.L.; Tafuri, W. Canine visceral leishmaniasis: a histopathological study of lymphnodes. Acta Tropica. 2004 Sep; 92(1): 43-53. Disponível em: http://www.sciencedirect.com/science/article/pii/S0001706X04001159. Inglês.

9. Fauré-Brac, G. La leishmaniose canine. Rev Path Comp d'Hygiène Genève. 1933. 33: 648-649.

10.Donatien, A.; Lestoquard, F. Notes sur la leishmaniose viscerale canine. Le Bulletin de la Société de pathologie exotique. 1935. 28: 426-431.

11. Keenan, C.M.; Hendricks, L.D.; Lightner, L.; Webster, H.K.; Johnson, A. Visceral Leishmaniasis in the German Shepherd dog. I. Infection, clinical disease, and clinical pathology. Veterinary Parasitology. 1984 Jan; 21(1): 74-9. Disponível em: http://vet.sagepub.com/content/21/1/74.long. Inglês.

12. Santana, C.C.; Vassallo, J.; de Freitas, L.A.; Oliveira, G.G.; Pontes-de-Carvalho, L.C.; dos-Santos, W.L. Inflammation and structural changes of splenic lymphoid tissue in visceral leishmaniasis: A study on naturally infected dogs. Parasite Immunology. 2008 Oct; 30(10): 515-24. Disponível em: http://onlinelibrary.wiley.com/doi/10.1111/j.1365-3024.2008.01051.x/pdf. Inglês.

13. Rhoads, M. L.; Fetterer, R.H. Extracellular matrix: a tool for defining the extracorporeal function of parasite protease. Parasitology Today. 1997 Mar; 13(3): 119-22. Disponível em: http://dx.doi.org/10.1016/S0169-4758(96)40011-4. Inglês.

14.Andrade, Z.A. Extracellular matrix degradation in parasitic diseases. Brazilian Journal of Medical and Biological Research. 1994 Sep; 27(9): 2273-81.

15. Mcgwire B.S.; Chang K.P.; Engman D.M. Migrationthrough the extracellular matrix by the parasitic protozoan Leishmania is enhanced by surface metalloprotease gp63. Infection and Immunity. 2003 Feb; 71(2): 1008-10. Disponível em: http://www.ncbi.nlm.nih.gov/pmc/articles/PMC145380/. Inglês.

16. Von der Mark H.; Von der Mark K.; Gay, S. Study of differential collagen synthesis during development of the chick embryo by immunofluorescence. Developmental Biology. 1976 Feb; 48(2): 237-49. Disponível em: http://www.sciencedirect.com/science/article/pii/0012160676900889. Inglês.

17. Abreu-Silva, A. L.; Calabrese, K. S.; Mortara, R. A.; Tedesco, R.C; Cardoso, F. O.; Carvalho, L. O. P.; Gonçalves da Costa, S. C. Extracellular matrix alterations in experimental murine Leishmania (L.) amazonensis infection. Parasitology. 2004 Apr; 128 (Pt 4): 385-90. Disponível em: http://www.ecb.epm.br/ ramortara/pdf/Abreu-Silva-2004.pdf. Inglês.

18. Lachaud, L.; Marchergui-Hammami, S.; Chabbert, E.; Dereure, J.; Dedet, J. P.; Bastien, P. Comparison of six PCR methods using peripheral blood for detection of canine visceral Leishmaniasis. Journal of Clinical Microbiology. 2002 Jan; 40(1): 210-215. Disponível em: http://jcm.asm.org/content/40/1/210. Inglês.

19. Kaneko JJ.; Mattheeuws D.; Rottiers RP.; Vermeulen A. Renal function, insulin secretion, and glucose tolerance in mild streptozotocin diabetes in the dog.. American Journal of Veterinary Research. 1978 May; 39(5):807-9. Disponível em: http://europepmc.org/abstract/MED/153115. Inglês.

20. Melo F.; Amaral M.; Oliveira P.; Lima W.; Andrade M.; Michalick M.; Raso P.; Tafuri W. Diffuse intralobular liver fibrosis in dogs naturally infected with Leishmania (Leishmania) chagasi. The American 
Journal of Tropical Medicine and Hygiene. 2008 Aug; 79(2): 198-204. Disponível em: http://www.ajtmh.org/content/79/2/198.long. Inglês.

21. Tafuri W.L.; Santos R.D.E.L.; Arantes R.M.; Goncalves R.; de Melo M.N.; Michalick M.S.; Tafuri W.L. An alternative immunohistochemical method for detecting Leishmania amastigotes in paraffin-embedded canine tissues. The Journal of Immunological Methods. 2004 Sep; 292(1-2): 17-23. Disponível em: http://www.sciencedirect.com/science/article/pii/S0022175904001930. Inglês.

22. Richard L. O. B.; Mark W.; Dorothy A. E. Analysis of Stained Objects in Histological Sections by Spectral Imaging and Differential Absorption. The Journal of Histochemistry \& Cytochemistry. 1999 Nov; 47(10): 1307-1313. Disponível em: http://jhc.sagepub.com/content/47/10/1307. Inglês.

23. Ciaramella P.; Oliva G.; de Luna R.; Gradoni L.; Ambrosio R.; Cortese L.; Scalone A \& Persechino A. A retrospective clinical study of canine leishmaniasis in 150 dogs naturally infected by $L$. infantum. Veterinary Record. 1997 Nov 22;141(21):539-43.

24. Ferrer L.; Aisa Mj.; Roura X.; Portús M. Serological diagnosis and treatment of canine leismaniasis. Veterinary Record. 1995 May 20;136(20):514-6. http://www.ncbi.nlm.nih.gov/pubmed/7660549. Inglês.

25.Giunchetti, R.C.; Mayrink, W.; Genaro, O.; Carneiro, C.M.; Corrêa-Oliveira, R..; Martins-Filho, O.A.; Marques, M.J.; Tafuri, W.L.; Reis, A.B. Relation between canine visceral leishmaniosis and the Leishmania (Leishmania) chagasi burden in dermal inflammatory foci. Journal of Comparative Pathology. 2006 Aug-Oct. 135(2-3): 100-7. Disponível em: http://www.sciencedirect.com/science/article/pii/S0021997506000594. Inglês.

26. Moura, E.P.; Ribeiro, R.R.; Sampaio, W.M.; Lima, W.G.; Alves, C.F.; Melo, F.A.; Melo, M.N.; Tafuri, W.L.; Tafuri, W.L.; Michalick, M.S.M. Histopathological and parasitological analysis of skin tissues biopsies from two distinct anatomical areas of the ears of dogs. Brazilian Journal of Veterinary Pathology. 2008. 1(1): 10-15. Disponível em: http://www.bjvp.org.br/files/pdf/01/08 01 003.pdf. Inglês.

27. Corbett, c.e.; Duarte, M.I.; Bustamante, S.E. Regression of diffuse intralobular liver fibrosis associated with visceral leishmaniasis. The American Journal of Tropical Medicine and Hygiene. 1993. 49: 616-624. Disponível em: http://www.ajtmh.org/content/49/5/616.long. Inglês.

28. Abranches, P.; Silva-Pereira, M.C.D.; Conceição-Silva, F.M.; Santos Gomes, G.M; Janz, G. Canine leishmaniasis: Pathological and ecological factors influencing transmission of infection. The Journal of Parasitology. 1991. 77(4): 557-561. Disponível em: http://www.jstor.org/stable/3283159. Inglês.

29. Xavier, S.C.; de Andrade, H.M.; Monte, S.J.; Chiarelli, I.M.; Lima, W.G.; Michalick, M.S.; Tafuri, W.L.; Tafuri, W.L. Comparison of paraffin-embedded skin biopsies from different anatomical regions as sampling methods for detection of Leishmania infection in dogs using histological, immunohistochemical and PCR methods. BMC Veterinary Research. 2006 Jun. 8:2-17. Disponível em: http://www.biomedcentral.com/1746$\underline{6148 / 2 / 17}$. Inglês.

30. Stanley, A.C.; Engwerda, C.R. Balancing immunity and pathology in visceral leishmaniasis. Immunology and Cell Biology. 2007 Feb-Mar; 85(2): 138-47. Disponível em: http://www.nature.com/icb/journal/v85/n2/pdf/7100011a.pdf. Inglês.

31. Lima, W.G.; Oliveira, P.S.; Caliari, M.V.; Gonçalves, R.; Michalick, M.S.; Melo, M.N.; Tafuri, W.L. Histopathological and immunohistochemical study of type 3 complement receptors (CD11b/CD18) in livers and spleens of asymptomatic and symptomatic dogs naturally infected with Leishmania (Leishmania) chagasi. Veterinary Immunology and Immunopathology. 2007 May 15; 117(1-2): 129-36. Disponível em: http://www.sciencedirect.com/science/article/pii/S0165242707000724. Inglês.

32. Weiss, L.; Gedulding, U.; Weidanz, W. Mechanism of the splenic control of murine malaria: reticular cell activation and the development of a blood-spleen barrier. American Journal of Anatomy. 1986 Jul; 176(3): 251-85. Disponível em: http://onlinelibrary.wiley.com/doi/10.1002/aja.1001760303/pdf. Inglês.

33.Alexandre-Pires, G.; Pais, D.; Correia, M.; Esperança PINA, J.A. Leishmaniosis-A report about the microvascular and cellular architecture of the spleen in Canis familiaris. Microscopy Reseach an Techinique. 2006 Apr; 69(4): 227-35. Disponível em: http://onlinelibrary.wiley.com/doi/10.1002/jemt.20267/pdf. Inglês. 